Article

\title{
Suppression of DNCB-Induced Atopic Skin Lesions in Mice by Wikstroemia indica Extract
}

\author{
So-Yeon Lee ${ }^{1,{ }^{\dagger}}$, No-June Park ${ }^{2,{ }^{\dagger}}$, Jonghwan Jegal ${ }^{1}$, Beom-Geun Jo ${ }^{1}$, Sangho Choi ${ }^{3}$, \\ Sang Woo Lee ${ }^{3}$, Md. Salah Uddin ${ }^{4}$, Su-Nam Kim ${ }^{2, *}$ and Min Hye Yang ${ }^{1, *}$ \\ 1 College of Pharmacy, Pusan National University, Busan 46241, Korea; s7315@naver.com (S.-Y.L.); \\ jhjegal@pusan.ac.kr (J.J.); dtc98103@pusan.ac.kr (B.-G.J.) \\ 2 Natural Products Research Institute, Korea Institute of Science and Technology, Gangneung 25451, Korea; \\ 115519@kist.re.kr \\ 3 International Biological Material Research Center, Korea Research Institute of Bioscience and Biotechnology, \\ Daejeon 34141, Korea; decoy0@kribb.re.kr (S.C.); ethnolee@kribb.re.kr (S.W.L.) \\ 4 Ethnobotanical Database of Bangladesh, Dhaka 1208, Bangladesh; Plantsofbd@gmail.com \\ * Correspondence: snkim@kist.re.kr (S.-N.K.); mhyang@pusan.ac.kr (M.H.Y.); Tel.: +82-33-650-3503 (S.-N.K.); \\ +82-51-510-2811 (M.H.Y.); Fax: +82-33-650-3419 (S.-N.K.); +82-51-513-6754 (M.H.Y.) \\ + These authors contributed equally to this work.
}

Received: 5 October 2019; Accepted: 3 January 2020; Published: 8 January 2020

\begin{abstract}
Wikstroemia indica (L.) C.A. Mey. is used in traditional Chinese medicine to treat inflammatory diseases such as arthritis and bronchitis. In this study, we aimed to investigate the effects of an ethanolic extract of $W$. indica on cutaneous inflammation in mice with 2,4-dinitrochlorobenzene (DNCB)-induced atopic dermatitis (AD). Dermal administration of W. indica ethanolic extract to DNCB-sensitized hairless mice with dermatitis, for two weeks, reduced erythema, scaling, and edema. Skin hydration was improved and transepidermal water loss was reduced at a $W$. indica concentration of $1 \%$. Furthermore, $W$. indica also significantly reduced serum IgE and IL-4 concentrations in our mouse model. These results suggest that $W$. indica has potential as a topical treatment for AD and as an adjunctive agent to control AD.
\end{abstract}

Keywords: Wikstroemia indica; 2,4-dinitrochlorobenzene; atopic dermatitis; transepidermal water loss; interleukin

\section{Introduction}

Atopic dermatitis (AD) is a chronic, relapsing inflammatory disease that is accompanied by representative symptoms, such as itching, redness, dry skin, and exudate. According to the Korean National Health and Nutrition Examination Survey (2016), the prevalence of AD in Korean adolescents was $25.1 \%$ [1]. In reality, children and adolescents account for more than half of AD patients, though in recent years, the proportion of adult $\mathrm{AD}$ patients has increased [2,3]. AD is a multifactor disorder caused by complex interactions between immunological, environmental, and genetic factors $[4,5]$, and its hallmarks are markedly elevated serum immunoglobulin E (IgE) and interleukin-4 (IL-4) levels, and a damaged skin barrier function $[6,7]$.

The skin is the first-line of defense system against external allergens, pollutants, and microbes, and maintains water homeostasis in the stratum corneum [8]. Skin damage increases the susceptibility to penetration of the skin barrier by foreign substances or microorganisms, and because many of these exogenous stressors are potential allergens, skin penetration can result in allergic reactions. Furthermore, allergic reactions increase the secretions of cytokines, which exacerbate skin barrier damage and initiate a vicious cycle [9]. Traditionally, AD is regarded as an allergic disease with an immunological etiology, and accordingly, immunomodulators such as topical corticosteroids and 
calcineurin inhibitors have been mainly used as therapeutic agents [10,11]. However, recent studies have shown that skin barrier damage per se might be a major cause of $\mathrm{AD}$, and this has resulted in novel pharmacotherapeutic developmental strategies [12]. For example, emollients provide a single barrier layer on skin and provide a safe and effective means of reducing skin penetration by allergens and maintaining skin hydration. Some clinical trials have shown emollients help AD in newborns without causing any side effects $[13,14]$.

Wikstroemia indica (L.) C.A. Mey. (Thymelaeaceae) is a shrub species of flowering plants that are native to Southeast Asia. W. indica has long been used in traditional Chinese medicine for treating arthritis, bronchitis, and syphilis [15], and scientific studies have shown that W. indica contains bioactive compounds (e.g., lignans, flavonoids, and coumarins) $[16,17]$. In addition, extracts or isolated compounds have been shown to have antitumor [18], anti-malarial [19], anti-inflammatory [20], antifungal, antimitotic, and antiviral [21] effects. However, no study has investigated the anti-AD effects of $W$. indica, and thus, in the present study, we investigated the anti-AD activity of $W$. indica ethanolic extract in a 2,4-dinitrochlorobenzene (DNCB)-induced murine model of atopic dermatitis.

\section{Materials and Methods}

\subsection{Plant Materials and Sample Preparation}

The stem and leaf parts of Wikstroemia indica (L.) C.A. Mey were collected in Zobra village, Hathazari Upazila, Chittagong, and the plant materials were authenticated by Dr. Sang Woo Lee (Korea Research Institute of Bioscience and Biotechnology) in 2014. A voucher specimen (accession number KRIB 0055091) of the retained material is preserved at the herbarium of KRIBB. The plant name and family name of Wikstroemia indica (L.) C.A. Mey. was checked with The Plant List on-line site (www.theplantlist.org; http://www.theplantlist.org/tpl1.1/record/tro-32000565) and was added to the Plant List (www.theplantlist.org). A voucher specimen (PNU-0026) was deposited at the Medicinal Herb Garden of Pusan National University. Dried stems and leaves of $W$. indica $(4 \mathrm{~kg}$ ) were prepared by chopping them into small millimeter-sized pieces. The plants prepared were extracted with $95 \%$ $\mathrm{EtOH}(12 \mathrm{~L} \times 3)$ and concentrated to dryness in vacuo to yield $W$. indica $\mathrm{EtOH}$ extract $(247.6 \mathrm{~g})$.

\subsection{Mouse Model}

SKH-1 hairless mice (female, six weeks old) were acquired from Orient Bio Inc. (Seongnam, Korea). Mice were housed in an air-controlled environment (RH $55 \pm 5 \%, 25 \pm 5^{\circ} \mathrm{C}$ ) under $12 \mathrm{~h}$ light and $12 \mathrm{~h}$ dark cycle until the experiment, and were provided with standard laboratory food and water ad libitum. All experimental procedures involving animals complied with the Guide for the Care and Use of Laboratory Animals of the National Institutes of Health (NIH Publication No. 85-23, 2011 revision). Procedures were approved by the Institutional Animal Care and Use Committee (IACUC) of Korea Institute of Science and Technology (Certification No. KIST-2016-011).

\subsection{DNCB-Induced AD Model and W. indica Extract Treatment}

Atopic dermatitis (AD) was induced in SKH-1 hairless mice using DNCB (2,4-dinitrochlorobenzene; Sigma-Aldrich, Seoul, Korea), based on previous literatures [22,23]. Briefly, the mice were acclimatized for one week and then divided into four groups ( $\mathrm{n}=7 /$ group), as follows; distilled water-treated controls (the CON group), DNCB-sensitized and vehicle-treated controls (DNCB + vehicle group), a DNCB-sensitized and a $1 \% W$. indica extract treatment group (the DNCB $+W$. indica group), and a DNCB-sensitized and a $1 \%$ pimecrolimus (Elidel ${ }^{\circledR}$ ) treated group (the DNCB + Elidel group). To induce AD-like skin lesions, $1 \%$ DNCB $(100 \mu \mathrm{L})$ dissolved in propylene glycol and $\mathrm{EtOH}(7: 3)$ was topically applied to dorsal skin, daily, for 8 days (days 0 to 7$)$. Mice were challenged with $0.1 \%$ DNCB $(100 \mu \mathrm{L})$ at 2-day intervals for 2 weeks (on days 8, 10,12,14,16, 18, and 20). Animals in the DNCB + W. indica group and in the DNCB + Elidel group were treated topically with $1 \% \mathrm{~W}$. indica $(100 \mu \mathrm{L})$ or $1 \%$ pimecrolimus cream twice daily, over the same two-week period, $4 \mathrm{~h}$ before DNCB administration. 
The eczema reaction and the degree of erythema, exudation, and excoriation were evaluated clinically. Mice were sacrificed and the dorsal skin tissue was excised after the final experiment (day 21) for histological examination. Blood was collected from abdominal aortas to determine serum $\operatorname{IgE}$ and IL-4 levels.

\subsection{Histological Analysis}

Dorsal skin tissues were collected from the SKH-1 hairless mice for histological analysis on day 21. Tissues were fixed in $10 \%$ formalin solution for $24 \mathrm{~h}$ and embedded in paraffin wax. Sections $(2-3 \mathrm{~mm}$ thick) were obtained using a microtome, placed on slides, and dried overnight at $37^{\circ} \mathrm{C}$. Staining was performed using hematoxylin and eosin ( $\mathrm{H} \& \mathrm{E})$ to determine changes in thickness of the epidermis or toluidine blue, which would indicate the changes in mast cell number. The slides were observed and photographed under a light microscope (Olympus CX31/BX51, Olympus Optical Co., Tokyo, Japan) and a fluorescence microscope (TE2000-U, Nikon Instruments Inc., Melville, NY, USA).

\subsection{Measurement of IgE and IL-4 Levels by ELISA}

Total levels of serum IgE and IL-4 were measured using enzyme-linked immunosorbent assay kits (ELISA, eBioscience, San Diego, CA, USA). Blood samples were collected from abdominal aortas and centrifuged at $10,000 \mathrm{rpm}$ for $15 \mathrm{~min}$ at $4{ }^{\circ} \mathrm{C}$. The serum samples obtained were stored at $-80^{\circ} \mathrm{C}$ until required.

\subsection{Measurement of Transepidermal Water Loss and Skin Hydration}

The transepidermal water loss (TEWL) was measured using an evaporimeter (Tewameter TM210; Courage and Khazaka, Cologne, Germany). Skin hydration and skin pH were evaluated using a SKIN-O-MAT unit (Cosmomed, Ruhr, Germany). All measurements were performed weekly in an environment of $50 \pm 5 \%$ relative humidity at $25 \pm 5{ }^{\circ} \mathrm{C}$ temperature.

\subsection{Analysis of HPLC/MS}

High-performance liquid chromatography/mass spectrometry (HPLC/MS) analyses were carried out in Agilent 6530 Accurate-Mass Q-TOF LC/MS system (Agilent Technologies). The chromatographic separation was performed using a Poroshell 120 EC-C18 column $(3.0 \times 100 \mathrm{~mm}, 2.7 \mu \mathrm{m}$, Agilent Technologies, Little Fall, DE, USA), and the gradient elution used mobile phase A (acetonitrile) and B (ultrapure water). The gradient elution program was set as: 10\% A (0-5 min), 10\%-70\% A (5-30 min), and 70\% A (30-40 min). The flow rate was maintained at $0.3 \mathrm{~mL} / \mathrm{min}$, and UV detection at $254 \mathrm{~nm}$. HPLC/MS spectra was acquired in positive ionization mode with a mass range of 100-1,500 m/z.

\subsection{Statistical Analysis}

Results were obtained using at least two independent experiments. The data were analyzed by one-way analysis of variance (ANOVA) and Tukey's multiple comparisons post-hoc analysis. Results were expressed as means \pm SEMs and were considered to be statistically significant for $p$-values $<0.05$.

\section{Results}

\subsection{Effects of W. indica Extract on AD-Like Symptoms in the DNCB Hairless Mouse Model}

To investigate anti-atopic effects of $W$. indica on DNCB-sensitized skin lesions, dermatitis severities were evaluated using skin lesion images. The procedure used to establish the DNCB-induced AD murine model is shown in Figure 1A. Severe AD-like symptoms, i.e., dried skin, cornification, exudation, and erythema, were observed on the dorsal skins of hairless mice after 3 weeks exposure to DNCB. The application of $1 \%$ W. indica during the 2-week challenge period (days 8-21) significantly relieved AD-like symptoms (Figure 1B). 
(A)

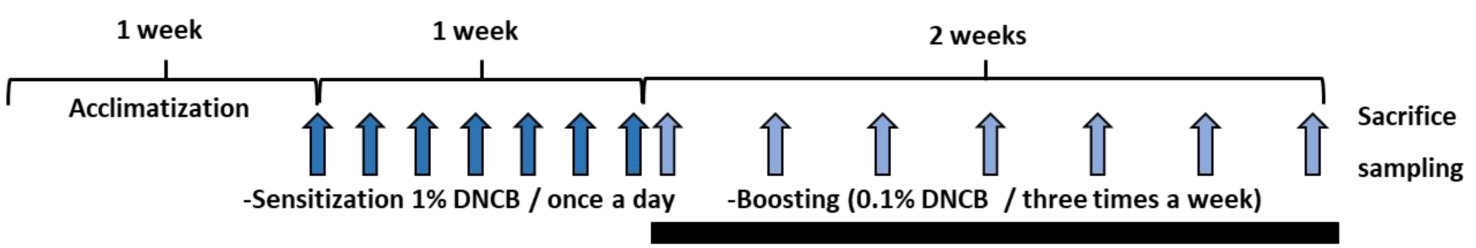

$1 \%$ W. indica EtOH extract (WDE) and 1\% Elidel cream

topical application (twice a day)

(B)

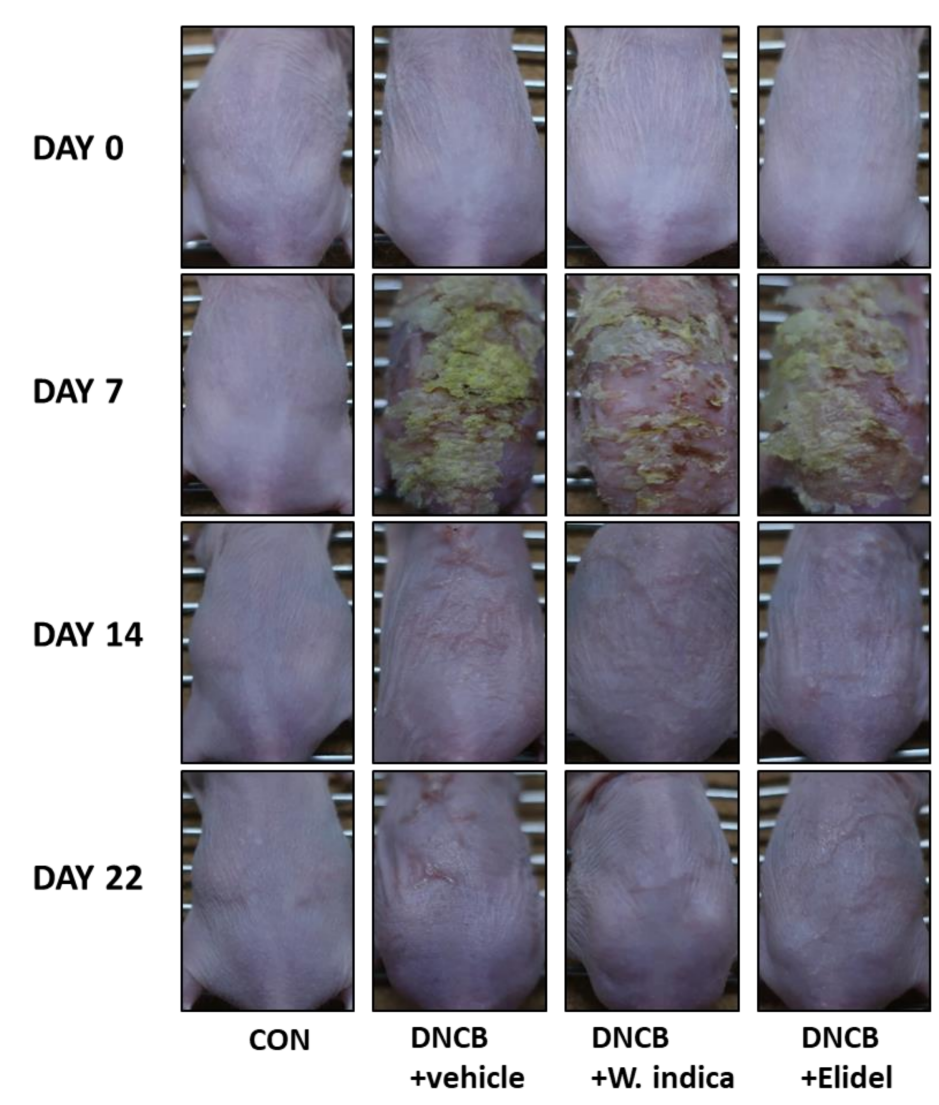

Figure 1. Effects of $W$. indica on the development of 2,4-dinitrochlorobenzene (DNCB)-induced AD-like skin lesions in SKH-1 hairless mice. (A) Schematic representation of the experiment. (B) Clinical features of DNCB-induced AD-like skin symptoms. CON: vehicle control group; DNCB + vehicle: DNCB-treated control group; DNCB + W. indica: DNCB plus 1\% W. indica-extract treated group; and DNCB + Elidel: DNCB plus 1\% pimecrolimus treated group.

\subsection{Effects of W. indica on Epidermal Thickness in DNCB-Induced Atopic Mice}

To determine the histopathological features, the epidermal tissue of the dorsal skin was stained with $\mathrm{H} \&$ E. Staining sections revealed that the epidermal tissue of the dorsal skin was about 2.5 times thicker in the DNCB $(75.25 \mu \mathrm{m})$ than in the CON (Figure 2A), dorsal skin dermal thicknesses were $33.5 \%$ and $44.4 \%$ lower in the DNCB + W. indica and DNCB + Elidel groups than in the DNCB group (Figure 2B). 
(A)

DNCB

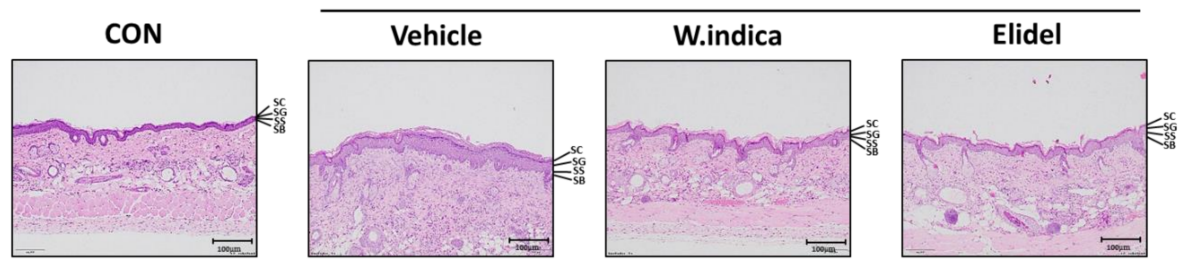

SC: Stratum corneum, SG : Stratum granulosum, SS : Stratum spinosum, SB : Stratum basale

(B)

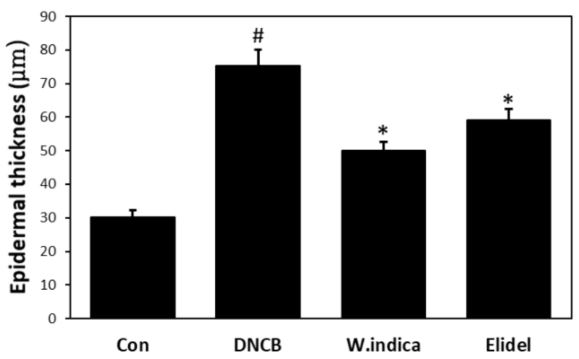

Figure 2. Effects of $W$. indica extract on hematoxylin and eosin ( $\mathrm{H} \& \mathrm{E})$ histopathology findings and epidermal thickness. (A) H \& E staining result. (B) Epidermal thickness. Results are expressed as the means \pm SEMs of two independent experiments. ${ }^{\#} p<0.05$ vs. the CON group; ${ }^{*} p<0.05$ vs. the DNCB group. $\mathrm{CON}$ : vehicle control group; $\mathrm{DNCB}: \mathrm{DNCB}+$ vehicle treated group; $\mathrm{DNCB}+W$. indica: $\mathrm{DNCB}$ and $1 \%$ W. indica extract treated group; and DNCB + Elidel: DNCB and 1\% pimecrolimus treated group.

\subsection{Effects of W. indica on Mast Cell Infiltration in DNCB-Induced Atopic Mice}

Toluidine blue staining was applied to AD-affected dorsal skin tissue samples to observe changes in mast cell numbers. The toluidine blue mast stained cell numbers were greater in the DNCB than in the CON (Figure 3A), but were 38.3\% and 33.3\% lower in the DNCB + W. indica and DNCB + Elidel, respectively, than in the DNCB (Figure $3 \mathrm{~B}$ ).

(A)

\section{DNCB}
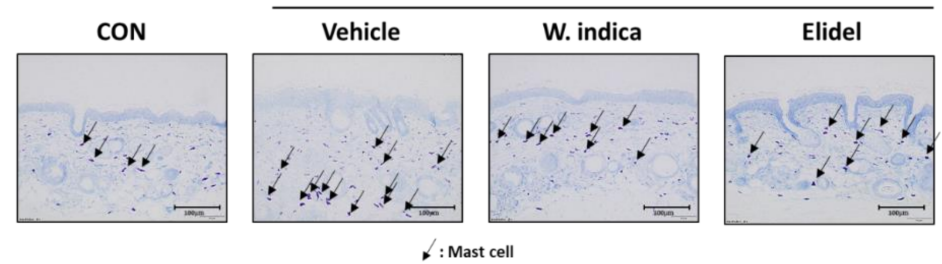

(B)



Figure 3. Effects of $W$. indica extract on toluidine blue staining findings and mast cell numbers in dermal tissues. (A) Toluidine blue staining result. (B) Mast cell numbers. Results are expressed as the means \pm SEMs of two independent experiments. ${ }^{\#} p<0.05$ vs. the CON group; ${ }^{*} p<0.05$ vs. the DNCB group. CON: vehicle control group; DNCB: DNCB + vehicle treated group; DNCB + W. indica: DNCB and 1\% W. indica extract treated group; and DNCB + Elidel: DNCB and 1\% pimecrolimus treated group. 


\subsection{Effects of W. indica Extract on Serum IgE and IL-4 Levels in DNCB-Induced Atopic Mice}

Serum level of IgE was 4.9-fold higher and IL-4 was 3.76-fold higher in the DNCB than in the CON but $33 \%$ and $34.2 \%$ lower, respectively, in the DNCB + W. indica than in the DNCB (Figure 4A,B, respectively).

(A)

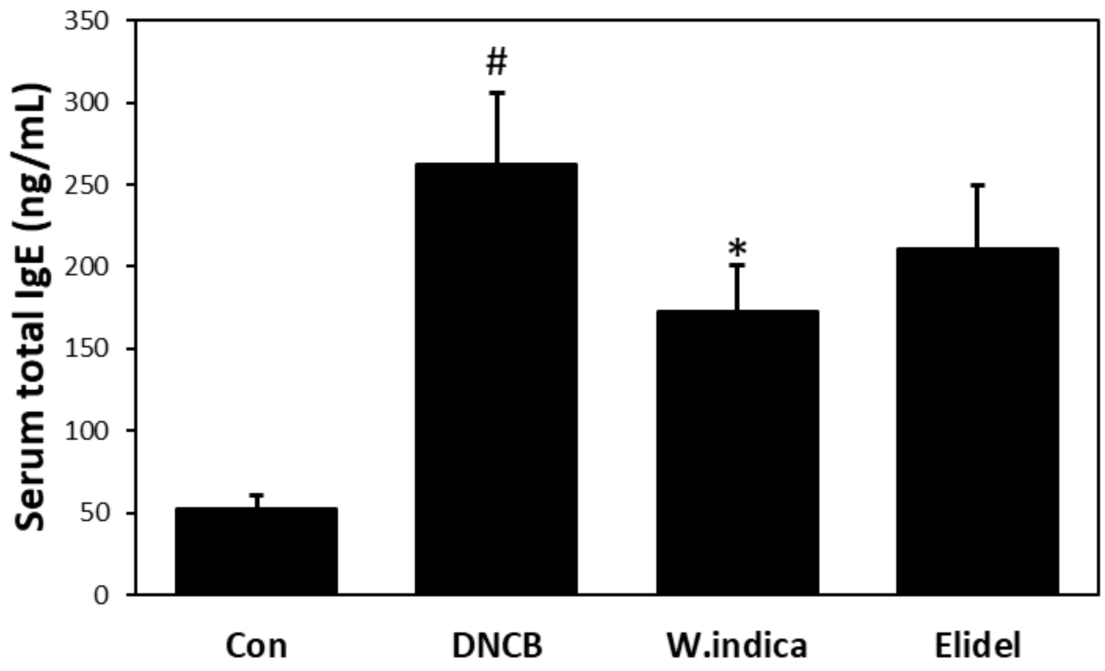

(B)

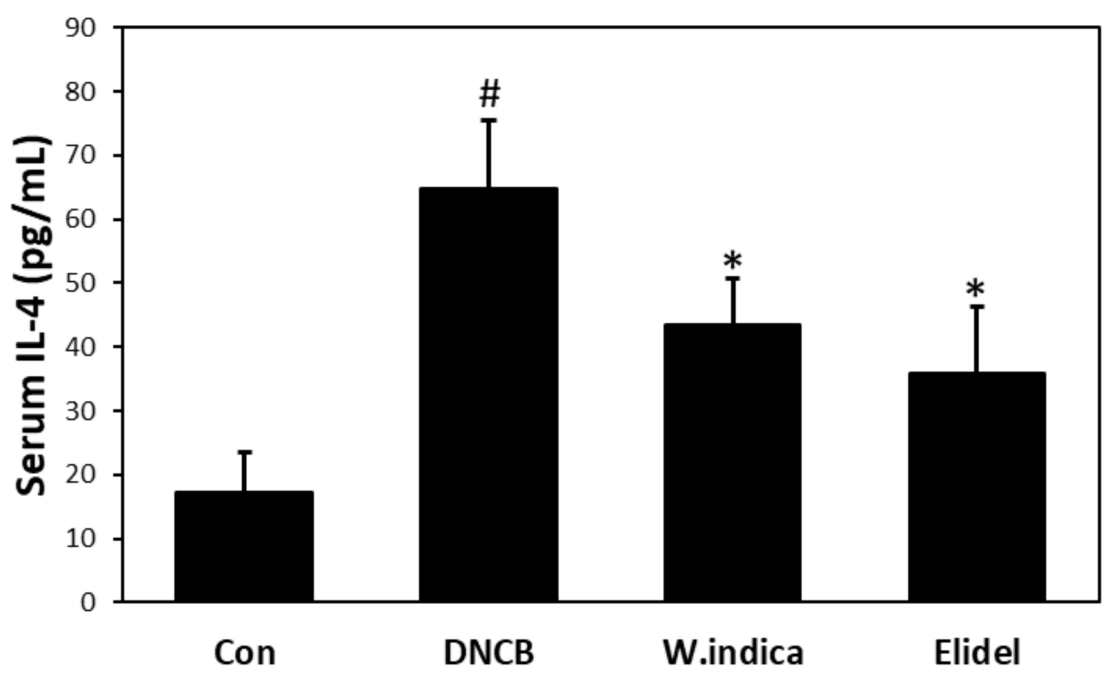

Figure 4. Effects of $W$. indica on serum IgE and IL-4 levels. (A) Serum IgE levels. (B) Serum IL-4 levels. Results are expressed as the means \pm SEMs $(n=7)$ of two independent experiments. ${ }^{\#} p<0.05$ vs. the CON group; ${ }^{*} p<0.05$ vs. the DNCB group. CON: vehicle control group; DNCB: DNCB + vehicle treated group; $\mathrm{DNCB}+W$. indica: $\mathrm{DNCB}$ and $1 \% W$. indica extract treated group; and DNCB + Elidel: DNCB and $1 \%$ pimecrolimus treated group.

\subsection{Effects of W. indica Extract on Skin Barrier Function in DNCB-Induced Atopic Mice}

TEWL and skin hydration, which are quantitative indicators of skin barrier function, were both found to deteriorate rapidly in the DNCB group. More specifically, TEWL was approximately 4-fold higher in the DNCB than in the CON (103.15 vs. $25.08 \mathrm{~g} / \mathrm{m}^{2} / \mathrm{h}$ ) (Figure $\left.5 \mathrm{~A}\right)$. In addition, skin hydration was $70 \%$ lower in the DNCB (13.68\% vs. 47.58 , respectively) (Figure 5B). However, TEWL was reduced to $21.7 \%$ in the DNCB $+W$. indica group (Figure $4 \mathrm{~A}$ ) and skin hydration was improved to $17.83 \%$ in the $\mathrm{DNCB}+W$. indica group (Figure 4B). 
(A)

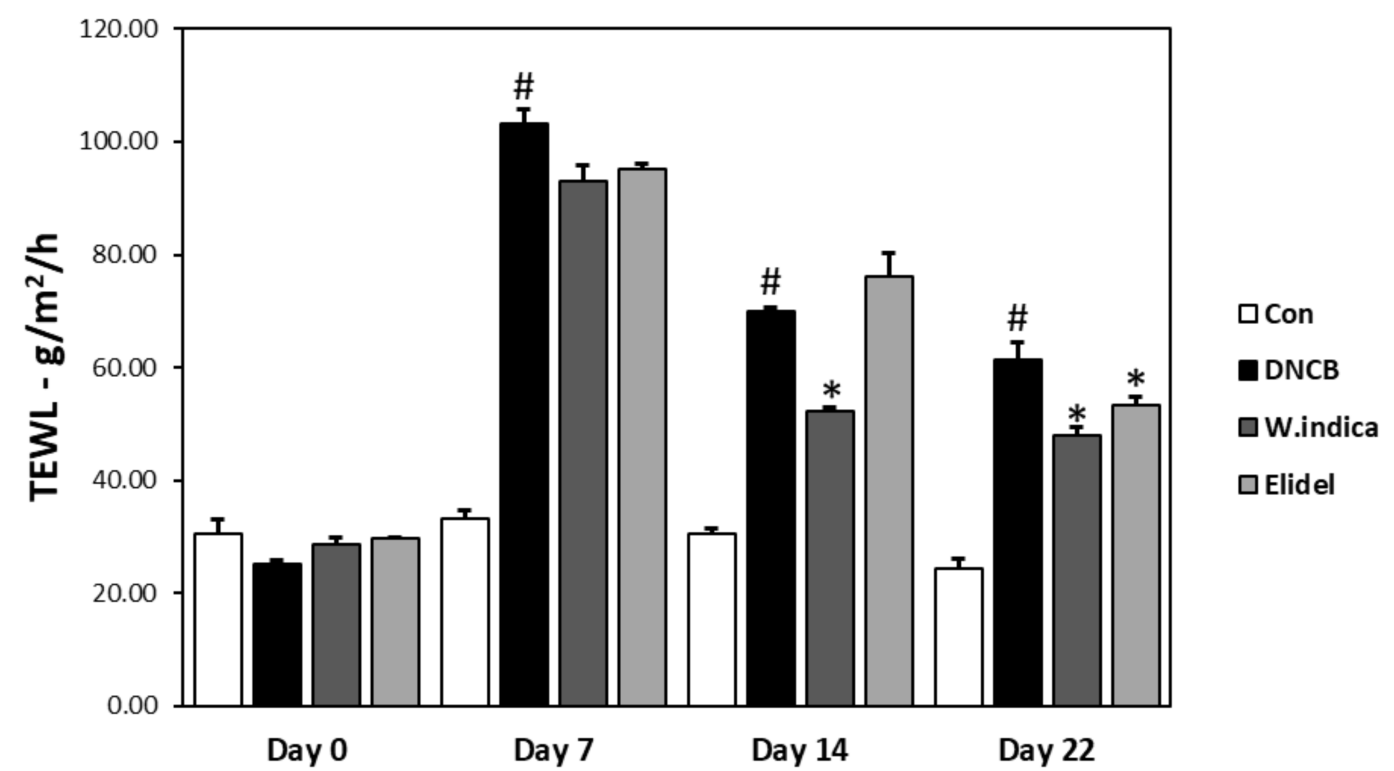

(B)

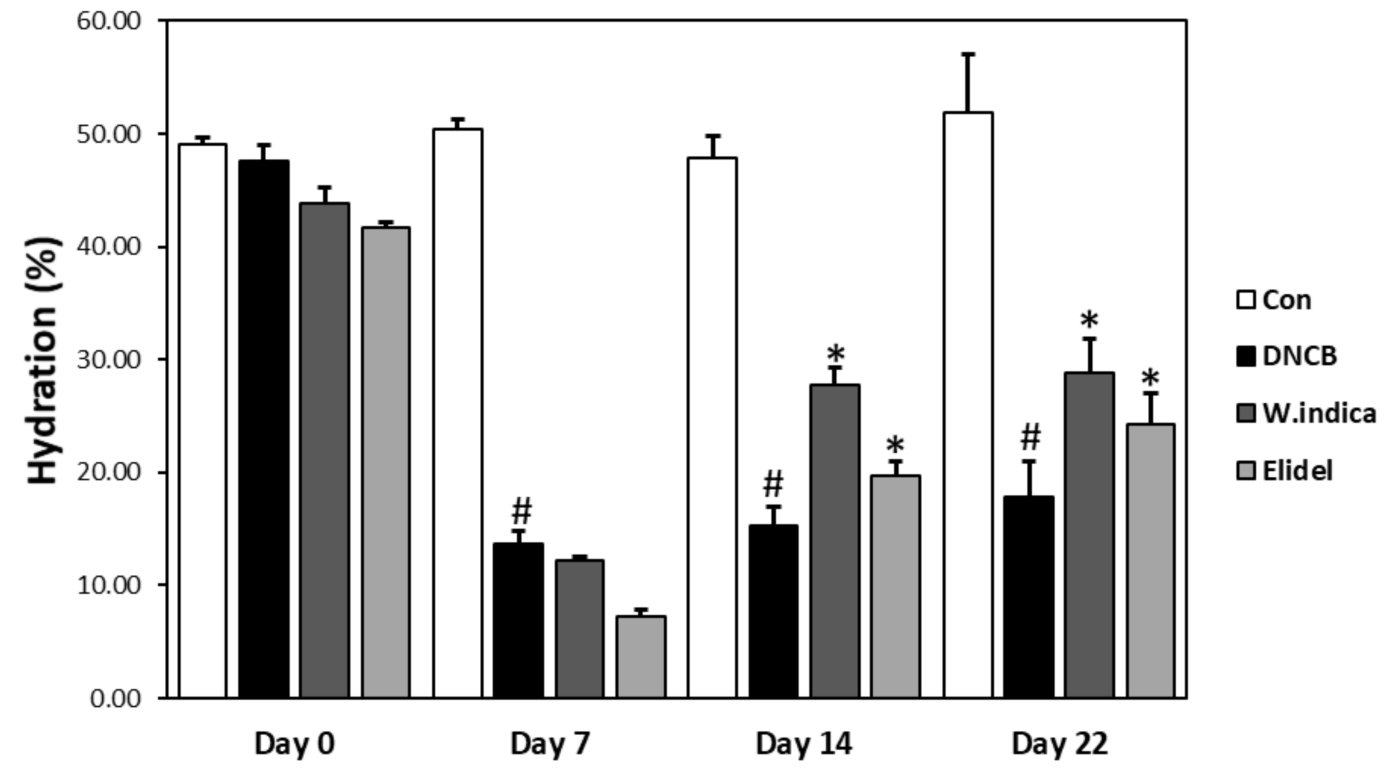

Figure 5. Effects of W. indica extract on skin barrier function. (A) Transepidermal water loss (TEWL). (B) Skin hydration values. Results are expressed as the means \pm SEMs $(n=7)$ of two independent experiments. ${ }^{\#} p<0.05$ vs. the CON group; ${ }^{*} p<0.05$ vs. the DNCB group. CON: vehicle control group; DNCB: $\mathrm{DNCB}+$ vehicle treated group; $\mathrm{DNCB}+W$. indica: $\mathrm{DNCB}$ and $1 \% W$. indica extract treated group; and DNCB + Elidel: DNCB and 1\% pimecrolimus treated group.

\subsection{The Phytochemical Characterization of W. indica Using the High-Performance Liquid} Chromatography/Mass Spectrometry (HPLC/MS)

A HPLC/MS method for analyzing phenolic compounds in W. indica EtOH extract was developed. For the simultaneous determination of the main compounds of $W$. indica, the optimum analytical condition was investigated. The optimal mobile phase, which consisted of acetonitrile/water, was subsequently employed for the analysis of $W$. indica and led to a good resolution and satisfactory peak shape. The presence of three compounds, 1: umbelliferone (m/z 161.0264 at $\left.t_{\mathrm{R}} 12.368 \mathrm{~min}\right)$, 2: quercitrin (m/z 447.0994 at $\left.t_{\mathrm{R}} 22.718 \mathrm{~min}\right)$, and 3: daphnoretin $\left(\mathrm{m} / \mathrm{z} 351.0562\right.$ at $\left.t_{\mathrm{R}} 27.377 \mathrm{~min}\right)$ in $W$. indica was confirmed by a comparison of its UV spectrum and retention time of each standard compound (Figure 6A,B). 
(A)

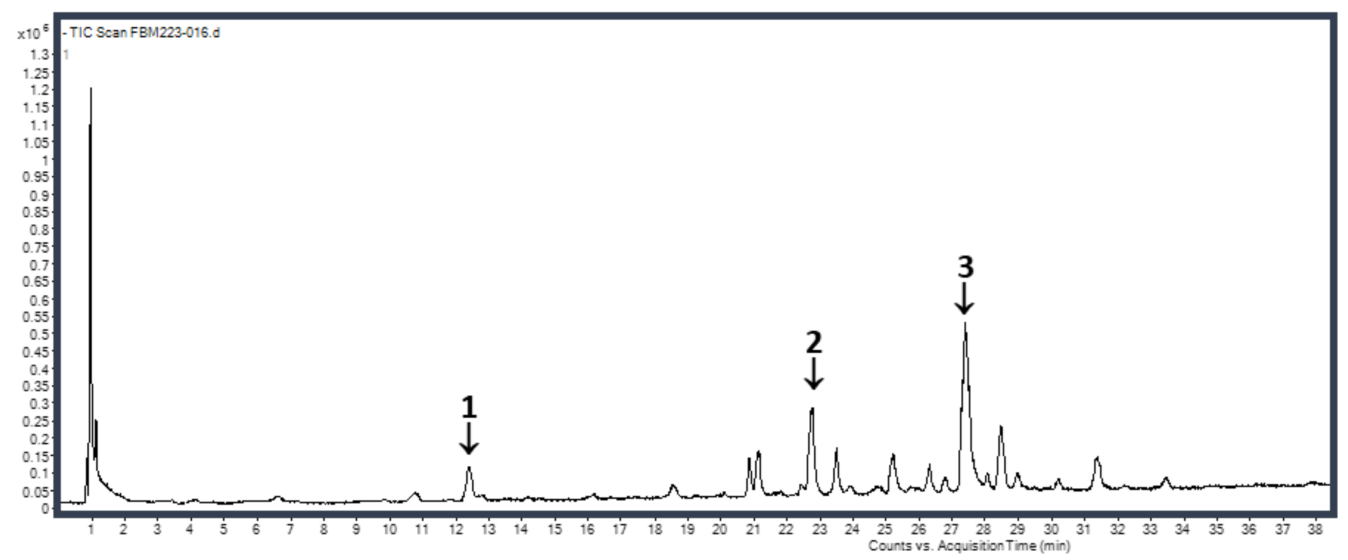

(B)<smiles>O=c1ccc2ccc(O)cc2o1</smiles>

1<smiles>C[C@@H]1O[C@H](OC2C(=O)c3c(O)cc(O)cc3OC2c2ccc(O)c(O)c2)[C@H](O)[C@H](O)[C@@H]1O</smiles>

2<smiles>COc1cc2cc(Oc3ccc4ccc(=O)oc4c3)c(=O)oc2cc1O</smiles>

3

Figure 6. HPLC chromatogram of the phenolic compounds of Wikstroemia indica (A) and the chemical structures of its major compounds (B). Phytochemical characterization of the W. indica EtOH extract was performed using HPLC/MS. 1: umbelliferone ( $\left.t_{\mathrm{R}} 12.368 \mathrm{~min}\right), 2$ : quercitrin $\left(t_{\mathrm{R}} 22.718 \mathrm{~min}\right)$, and 3: daphnoretin $\left(t_{\mathrm{R}} 27.377 \mathrm{~min}\right)$.

\section{Discussion}

Wikstroemia species are still used as a herbal traditional medicines in China to treat various inflammatory conditions $[17,24]$. W. indica, a member of the Wikstroemia genus, is listed in Chinese pharmacopoeia under the name 'liao ga wang' and is marketed as an over-the-counter product, as an anti-inflammatory agent [24]. In recent years, many studies have demonstrated the anti-inflammatory and anti-viral effects of the members of the Wikstroemia genus [17,25]. Furthermore, W. indica has been shown to contain many phytochemicals, such as flavonoids, lignans, and coumarins, which have all got potent anti-inflammatory effects $[25,26]$.

Previous studies on plants of the genus Wikstroemia have shown that its crude extracts have immunomodulatory, anti-inflammatory, and anti-allergic effects in murine models [17,20,21]. However, no systematic attempt has been made to determine the effect of $W$. indica on AD, and thus, we investigated the anti-atopic effects of the airborne parts of $W$. indica ethanolic extract in a DNCB-induced model of $\mathrm{AD}$ in hairless mice. We found $1 \% \mathrm{~W}$. indica markedly attenuated DNCB-sensitized scratching behavior and skin lesion severity, such that it prevented the increase of TEWL and reduction of skin hydration induced by DNCB. A reduced epidermal barrier function is considered to be a major predisposing factor of $\mathrm{AD}$, and thus, the use of moisturizers offers a first-line therapy for the management of mild $\mathrm{AD}[27,28]$. From this point of view, it is possible that $W$. indica extract helps maintain the skin barrier 
function, and thus, ameliorated atopic skin symptoms. Future studies are required to evaluate the moisturizing effects of $W$. indica extract in patients with AD.

According to our findings, $W$. indica extract markedly inhibited IL-4 overexpression in the serum of our murine model. The inhibitory effects of $W$. indica on atopic skin symptoms might be in part due to the decrease in IL-4 and IgE levels. IL-4 inhibition might prevent the differential development of Th0 into Th2 cells, IgE class switching, and the degranulation of mast cells by IgE, which helps lower allergic responses [29]. Serum IgE level elevations in AD patients are influenced by activation and the secretion of IL- 4 by Th 2 cells (type 2 helper T cells) [30], and it has been reported that IL- 4 acts as an essential factor that promotes B cells to the IgE pathway [31,32]. Recent studies have shown that IL-4 enhances the productions of chemokines, such as MCP-1 and eotaxin, which increase the infiltrations of Th2 cells, eosinophils, and macrophages into skin lesion [33-35]. IL-4 also contributes to the impairment of barrier homoeostasis, and the proteins filaggrin, loricrin, and involucrin produced by keratinocytes play an essential role in skin barrier recovery. The genes of these proteins are down-regulated when IL-4 is overexpressed and this prevents the skin barrier from functioning properly [36,37]. Therefore, we suggest treatment with $W$. indica extract might accelerate skin barrier recovery in AD-like skin lesions by suppressing IL-4 secretion by Th2-type cells.

Collectively, the present study showed that the ethanolic extract of $W$. indica significantly suppressed DNCB-sensitized AD, by reducing epidermal thickness and mast cell infiltration in our murine model. Wikstroemia indica extract showed decreases in serum IgE and the suppression of IL-4 levels in DNCB-induced AD mice. In addition, W. indica extract markedly suppressed DNCB-induced skin barrier impairment and skin dehydration in our AD murine model. Furthermore, this study provided evidence in support of the protective effects of $W$. indica for the treatment of inflammatory skin diseases.

Author Contributions: S.-N.K. and M.H.Y. designed the study; S.-Y.L., N.-J.P., J.J., and B.-G.J. performed the experiments; S.C., S.W.L., and M.S.U. interpreted results; S.-Y.L., and M.H.Y. drafted the manuscript. All authors have read and agreed to the published version of the manuscript.

Funding: This study was funded by a grant from the Bio \& Medical Technology Development Program of the National Research Foundation (NRF) funded by the Ministry of Science \& ICT (grant Nos. NRF-2019M3A9I3080263, NRF-2019M3A9I3080265, and NRF-2019M3A9I3080266) and by the National Research Foundation of Korea (NRF) grant, funded by the Ministry of Science, ICT \& Future Planning (NRF-2016K1A1A8A01938595).

Conflicts of Interest: The authors have no conflict of interest to declare.

\section{References}

1. Lee, J.H.; Han, K.D.; Park, Y.G.; Lee, J.Y.; Park, Y.M. Prevalence of atopic dermatitis in Korean children based on data from the 2008-2011 Korean National Health and Nutrition Examination Survey. Allergy Asthma Immunol. Res. 2016, 8, 79-83. [CrossRef] [PubMed]

2. Pyun, B.Y. Natural history and risk factors of atopic dermatitis in children. Allergy Asthma Immunol. Res. 2015, 7, 101-105. [CrossRef] [PubMed]

3. Megna, M.; Patruno, C.; Villani, A.; Balato, A.; Monfrecola, G.; Ayala, F.; Balato, N. Systemic treatment of adult atopic dermatitis: A review. Dermatol. Ther. 2017, 7, 1-23. [CrossRef]

4. Bin, L.; Leung, D.Y. Genetic and epigenetic studies of atopic dermatitis. Allergy Asthma Clin. Immunol. 2016, 12,1-14. [CrossRef] [PubMed]

5. Leung, D.Y.; Boguniewicz, M.; Howell, M.D.; Nomura, I.; Hamid, Q.A. New insights into atopic dermatitis. J. Clin. Invest. 2004, 113, 651-657. [CrossRef] [PubMed]

6. Tang, M.; Kemp, A.; Varigos, G. IL-4 and interferon-gamma production in children with atopic disease. Clin. Exp. Immunol. 1993, 92, 120-124. [CrossRef]

7. Jensen, J.M.; Pfeiffer, S.; Witt, M.; Bräutigam, M.; Neumann, C.; Weichenthal, M.; Schwarz, T.; Fölster-Holst, R.; Proksch, E. Different effects of pimecrolimus and betamethasone on the skin barrier in patients with atopic dermatitis. J. Allergy Clin. Immunol. 2009, 123, 1124-1133. [CrossRef]

8. Rawlings, A.V.; Harding, C.R. Moisturization and skin barrier function. Dermatol. Ther. 2004, 17, 43-48. [CrossRef] 
9. Mori, T.; Ishida, K.; Mukumoto, S.; Yamada, Y.; Imokawa, G.; Kabashima, K.; Kobayashi, M.; Bito, T.; Nakamura, M.; Ogasawara, K.; et al. Comparison of skin barrier function and sensory nerve electric current perception threshold between IgE-high extrinsic and IgE-normal intrinsic types of atopic dermatitis. Br. J. Dermatol. 2010, 162, 83-90. [CrossRef]

10. Atherton, D.J. Topical corticosteroids in atopic dermatitis. BMJ 2003, 327, 942-943. [CrossRef]

11. Ashcroft, D.M.; Dimmock, P.; Garside, R.; Stein, K.; Williams, H.C. Efficacy and tolerability of topical pimecrolimus and tacrolimus in the treatment of atopic dermatitis: Meta-analysis of randomized controlled trials. BMJ 2005, 330, 1-9. [CrossRef]

12. Elias, P.M.; Schmuth, M. Abnormal skin barrier in the etiopathogenesis of atopic dermatitis. Curr. Allergy Asthma Rep. 2009, 9, 265-272. [CrossRef]

13. Simpson, E.L.; Chalmers, J.R.; Hanifin, J.M.; Thomas, K.S.; Cork, M.J.; McLean, W.H.; Brown, S.J.; Chen, Z.; Chen, Y.; Williams, H.C. Emollient enhancement of the skin barrier from birth offers effective atopic dermatitis prevention. J. Allergy Clin. Immunol. 2014, 134, 818-823. [CrossRef] [PubMed]

14. Simpson, E.L.; Berry, T.M.; Brown, P.A.; Hanifin, J.M. A pilot study of emollient therapy for the primary prevention of atopic dermatitis. J. Am. Acad. Dermatol. 2010, 63, 587-593. [CrossRef] [PubMed]

15. Ho, W.S.; Xue, J.Y.; Sun, S.S.; Ooi, V.E.; Li, Y.L. Antiviral activity of daphnoretin isolated from Wikstroemia indica. Phytother. Res. 2010, 24, 657-661.

16. Wang, L.Y.; Unehara, N.; Kitanaka, S. Lignans from the roots of Wikstroemia indica and their DPPH radical scavenging and nitric oxide inhibitory activities. Chem. Pharm. Bull. 2005, 53, 1348-1351. [CrossRef]

17. Li, Y.M.; Zhu, L.; Jiang, J.G.; Yang, L.; Wang, D.Y. Bioactive components and pharmacological action of Wikstroemia indica (L.) CA Mey and its clinical application. Curr. Pharm. Biotechnol. 2009, 10, 743-752. [CrossRef] [PubMed]

18. Lee, K.H.; Tagahara, K.; Suzuki, H.; Wu, R.Y.; Haruna, M.; Hall, I.H.; Huang, H.C.; Ito, K.; Iida, T.; Lai, J.S. Antitumor agents. 49. Tricin, kaempferol-3-0- $\beta$-D-Glucopyranoside and (+)-nortrachelogenin, antileukemic principles from Wikstroemia indica. J. Nat. Prod. 1981, 44, 530-535. [CrossRef] [PubMed]

19. Nunome, S.; Ishiyama, A.; Kobayashi, M.; Otoguro, K.; Kiyohara, H.; Yamada, H.; Omura, S. In vitro antimalarial activity of biflavonoids from Wikstroemia indica. Planta Med. 2004, 70, 76-78. [PubMed]

20. Wang, L.Y.; Unehara, T.; Kitanaka, S. Anti-inflammatory activity of new guaiane type sesquiterpene from Wikstroemia indica. Chem. Pharm. Bull. 2005, 53, 137-139. [CrossRef]

21. Hu, K.; Kobayashi, H.; Dong, A.; Iwasaki, S.; Yao, X. Antifungal, antimitotic and anti-HIV-1 agents from the roots of Wikstroemia indica. Planta Med. 2000, 66, 564-567. [CrossRef] [PubMed]

22. Kitamura, A.; Takata, R.; Aizawa, S.; Watanabe, H.; Wada, T. A murine model of atopic dermatitis can be generated by painting the dorsal skin with hapten twice 14 days apart. Sci. Rep. 2018, 8, 1-9. [CrossRef] [PubMed]

23. Lee, K.S.; Jeong, E.S.; Heo, S.H.; Seo, J.H.; Jeong, D.G.; Choi, Y.K. A novel model for human atopic dermatitis: Application of repeated DNCB patch in BALB/c mice, in comparison with NC/Nga mice. Lab. Anim. Res. 2010, 26, 95-102. [CrossRef]

24. Huang, W.; Zhang, X.; Wang, Y.; Ye, W.; Ooi, V.E.C.; Chung, H.Y.; Li, Y. Antiviral biflavonoids from Radix wikstroemiae (Liaogewanggen). Chin. Med. 2010, 5, 1-6. [CrossRef] [PubMed]

25. Nirmala, M.J.; Samundeeswari, A.; Sankar, P.D. Natural plant resources in anti-cancer therapy-A review. Res. Plant Biol. 2011, 1, 1-14.

26. Rastogi, R.P.; Dhawan, B.N. Anticancer and antiviral activities in Indian medicinal plants: A review. Drug Dev. Res. 1990, 19, 1-12. [CrossRef]

27. Kim, T.Y.; Park, N.J.; Jegal, J.; Choi, S.; Lee, S.W.; Hang, J.; Kim, S.N.; Yang, M.H. Chamaejasmine isolated from Wikstroemia dolichantha Diels suppresses 2, 4-dinitrofluoro-benzene-induced atopic dermatitis in SKH-1 hairless mice. Biomolecules 2019, 9, 697. [CrossRef] [PubMed]

28. Simpson, E.L. Atopic dermatitis: A review of topical treatment options. Curr. Med. Res. Opin. 2010, 26, 633-640. [CrossRef] [PubMed]

29. Gelmetti, C.; Wollenberg, A. Atopic dermatitis-all you can do from the outside. Br. J. Dermatol. 2014, 170, 19-24. [CrossRef] [PubMed]

30. Jujo, K.; Renz, H.; Abe, J.; Gelfand, E.W.; Leung, D.Y. Decreased interferon gamma and increased interleukin-4 production in atopic dermatitis promotes IgE synthesis. J. Allergy Clin. Immunol. 1992, 90, 323-331. [CrossRef] 
31. Kashiwada, M.; Levy, D.M.; McKeag, L.; Murray, K.; Schröder, A.J.; Canfield, S.M.; Traver, G.; Rothman, P.B. IL-4-induced transcription factor NFIL3/E4BP4 controls IgE class switching. Proc. Natl. Acad. Sci. USA 2010, 107, 821-826. [CrossRef] [PubMed]

32. Jabara, H.H.; Ahern, D.J.; Vercelli, D.; Geha, R.S. Hydrocortisone and IL-4 induce IgE isotype switching in human B cells. J. Immunol. 1991, 147, 1557-1560. [PubMed]

33. Ovsiy, I.; Riabov, V.; Manousaridis, I.; Michel, J.; Moganti, K.; Yin, S.; Liu, T.; Sticht, C.; Kremmer, E.; Harmsen, M.C.; et al. IL-4 driven transcription factor FoxQ1 is expressed by monocytes in atopic dermatitis and stimulates monocyte migration. Sci. Rep. 2017, 7, 1-9. [CrossRef] [PubMed]

34. Kaburagi, Y.; Shimada, Y.; Nagaoka, T.; Hasegawa, M.; Takehara, K.; Sato, S. Enhanced production of CC-chemokines (RANTES, MCP-1, MIP-1 $\alpha$, MIP-1 $\beta$, and eotaxin) in patients with atopic dermatitis. Arch. Dermatol. Res. 2001, 293, 350-355. [CrossRef] [PubMed]

35. Kagami, S.; Kakinuma, T.; Saeki, H.; Tsunemi, Y.; Fujita, H.; Nakamura, K.; Takekoshi, T.; Kishimoto, M.; Mitsui, H.; Torii, H.; et al. Significant elevation of serum levels of eotaxin-3/CCL26, but not of eotaxin-2/CCL24, in patients with atopic dermatitis: Serum eotaxin-3/CCL26 levels reflect the disease activity of atopic dermatitis. Clin. Exp. Immunol. 2003, 134, 309-313. [CrossRef] [PubMed]

36. Kim, B.E.; Leung, D.Y.; Boguniewicz, M.; Howell, M.D. Loricrin and involucrin expression is down-regulated by Th2 cytokines through STAT-6. Clin. Immunol. 2008, 126, 332-337. [CrossRef]

37. Howell, M.D.; Kim, B.E.; Gao, P.; Grant, A.V.; Boguniewicz, M.; DeBenedetto, A.; Schneider, L. Cytokine modulation of atopic dermatitis filaggrin skin expression. J. Allergy Clin. Immunol. 2009, 124, R7-R12. [CrossRef]

(C) 2020 by the authors. Licensee MDPI, Basel, Switzerland. This article is an open access article distributed under the terms and conditions of the Creative Commons Attribution (CC BY) license (http://creativecommons.org/licenses/by/4.0/). 